\title{
THE TREATMENT OF TRICHOMONAS VAGINITIS
}

Case 3. This patient had previously had practically continuous treatment for four months with no relief. There was a very severe degree of vaginitis. High fever was followed by complete relief for one week. Relapse then occurred, but the condition was very much improved. A second treatment was given followed by complete absence of signs and symptoms. She was discharged from hospital three weeks after treatment when her condition was still satisfactory. Sufficient time has not elapsed for any further observation on this patient to be made.

\section{Summary}

One hundred and eighty-nine patients were treated for trichomonas vaginitis, and of these sixty (thirty-two per cent) were found to have an associated gonococcal infection. Four schemes of treatment were used and a comparative assessment of their value attempted. The numbers were too few and too unequal to permit valuable conclusions to be drawn. The combination of sulphonamide by mouth and by local insufflation, with local treatment designed to cure the trichomonas vaginitis, was employed as a means of eliminating evident or undiagnosed gonococcal infection. A high proportion of relapses occurred which, it was considered, might be due to the short course of treatment rendered essential by the exigencies of the Service. High prolonged fever with premedication by sulphathiazole, and accompanied by the vaginal use of acetarsol tablets was employed in four cases.

\section{Conclusions}

(1) Trichomonas vaginitis is a difficult disease to treat and with the methods employed a high proportion of relapses occur.

(2) The standards of observation should be the same as for gonococcal infections.

(3) The absence of bacteriological evidence of coincident gonococcal infection cannot be accepted as a reliable method of excluding gonorrhoea in all cases. Bacteriological difficulties are much increased by the presence of the parasite.

(4) The practice of giving oral sulphonamides as a routine in the treatment of trichomonas infections has much to recommend it.

(5) The immediate clinical results obtained after high prolonged fever in cases of trichomonas vaginitis which have resisted all other forms of treatment justify a further trial of this method.

\section{REFERENCES}

Elden, C. A. (1942) Amer. J. Obstet. Gynec., 43, 1054.

Filler, W., Drezner, N., and Adamo, F. H. (1942) Amer. J. Obstet. Gynec., 43, 1057. Peterson, P. (1938) Amer. J. Obstet. Gynec., 35, 1004.

\section{DISCUSSION}

The President, Brigadier T. E. Osmond, speaking as a pathologist, said he was particularly interested in the diagnostic aspects. He had always held and was glad to have his view confirmed that dark ground microscopy was the easiest and best method of diagnosis, although there were other methods of identifying $T$. vaginalis. He had a distinguished gynaecological colleague who declared that he could smell the trichomonas. In his official capacity he had had a considerable fight to get rid of the expression " venereal warts," but he thought one could say that now the term was obsolete. With regard to treatment he also felt encouraged to hear that some patients were cured; perhaps it was in spite of treatment. Personally he did not think that they were ever cured and had never seen one who was. Perhaps hyperpyrexia was the solution.

Dr. Ingram asked if the speakers had any figures to show the percentage of patients who were married and who were single.

Wing-Cdr. G. L. M. McElligott wished to congratulate the two speakers on a very interesting joint paper. He believed that the trichomonas infestation in these cases of vaginitis was often not the whole of the story. He was very interested to hear the Vibrio alkaligenes mentioned. From two recent cases of resistant non-gonococcal urethritis in the male this organism had been recovered in pure culture; whether it was a causative organism or not he did not know, but the two patients had never had gonorrhoea and he was interested to hear that the organism had been found in company with the trichomonas.

He would like to hear from the meeting or the readers of the papers whether an oral arsenical such as atebrin had ever been tried for this condition. Squadron Leader Morton had told him that she had found that in women who had coincidental syphilis and were being treated with N.A.B. their trichomonas infestation did seem to improve. The matter had not been followed up, 


\section{THE BRITISH JOURNAL OF VENEREAL DISEASES}

but he had just been talking to a colleague who told him that he had been on the look-out for an improvement in such cases, but had not seen any. If the condition was a purely surface infestationes. then local medication with arsenic should clear it. If it went deeper then the arsenic would have to be applied either orally or by injections.

Major Marjorie Bolton said that she always felt that acetarsol seemed to be the best treatmentThe vaginitis apparently cleared up pathologically and clinically within a week. She admitted that relapses were common, but she had been impressed by the fact that the vaginitis usually cleared rapidly at the beginning. She was interested in the resistant case of trichomonas vaginitis but had not realized that it could resist the arsenical compounds to such an extent. She wonderedi whether by any chance the substance used could have been a particular batch of a stovarsol compound which the manufacturers had admitted was relatively ineffective, it having beencs produced when there were difficulties in obtaining the necessary starch. The older batches of stovarsol were excellent. Atebrin had been tried, but in her hands it had no effect on $T$. vaginitis. Perhaps the drug did not reach the trichomonas which was situated almost externally to the body $\overrightarrow{\vec{C}}$ in the vaginal secretions; at any rate it did not seem to attain a sufficient concentration to bew effective. She had noticed that patients receiving neoarsphenamine (NAB) did not show any improvement in their trichomonas condition.

Dr. Margaret Rorke said that from the two angles of diagnosis and treatment the addresses $\vec{\oplus}$ had been extremely instructive. Like others working on venereal diseases, her task was made distressful by the combination of gonorrhoea and trichomonas infestation. Either there was a tremendous increase in the incidence or venereologists had become more alert and were finding $\overrightarrow{.}$ the trichomonas very much more frequently. Dr. Morton had said that in the majority of her women patients there was not a high standard of personal hygiene and she also spoke of the necessity for strict cleanliness ; trichomonas, however, also occurred in the middle class womenwho had good food and had many baths. The one symptom common to all classes was thates there was always constipation associated with a loaded rectum. It seemed that these severe曹 trichomonas infestations were always associated with an intestinal stasis as well as lack of general cleanliness. The condition might well be called a venereal infection although it was not: one of the three acknowledged venereal diseases. The association of trichomonas with theo gonococcus was very frequent at the present time, and it was very difficult to make the patient $\frac{\mathbb{D}}{-}$ understand that two infections were present. The gonorrhoea usually responded very well to $\vec{C}$ treatment. After the tests of cure she always asked her patients to come back in three or four $\frac{6}{8}$ months, but often they returned much sooner and said that the discharge had returned. To the patient this relapse was gonorrhoea, and it was impossible for her to understand that this irritative trichomonas discharge was not a relapse of gonorrhoea.

With regard to treatment Dr. Rorke said she had been using gentian violet as a vaginal paint 5 following stovarsol or Devegan tablets in the majority of cases. Some of her patients were pregnant, but in a number of such cases this treatment had little or no effect ; and then insufflation with Picragol powder gave much better results, following simple douching or vaginal painting. ItD was only by pooling experience that they would understand and improve this distressing condition.

Lt.-Col. A. J. King, R.A.M.C., thought, with Dr. Morton, that it was an extraordinary thing that those engaged in the treatment of venereal diseases knew so little about this disease of which they saw so much. Many said and thought that there was another factor involved.in the disease $\frac{F}{0}$ Some said it was a streptococcus, some a $B$. Coli, others did not know, but the search was always for an organism other than the gonococcus which was so often associated with the disease. $\stackrel{\rho}{?}$ The association between trichomonas vaginitis and gonorrhoea was obscure but intimate, and the two organisms could be found together in a considerable proportion of cases. In other 3 cases there was strong reason to believe that gonococci were present, but could not be found Undoubtedly, in his view, the presence of the trichomonas made it more difficult to find theo gonococcus. He believed there was a tendency to underestimate the importance of the gonococcus 3 as a determining factor in keeping up the infection and to disregard the significance of this constant association.

In his own experience, which, of course, had been limited to venereal disease clinics, trichomonas $D$ vaginitis had always seemed to be a venereal infection coming on after exposure to possible을. infection. He knew that an interesting legend had sprung up regarding the transference of infection in swimming baths, but he did not believe there was one scrap of evidence to support the $N$ suggestion that infection could occur in this way. It was a comforting theory with which to reassure the anxious patient but there was no evidence on which it could be accepted as aO scientific fact.

He could not follow the point that Liston and Lees' investigation showed that trichomonas $\omega$ vaginitis was not a venereal complaint. The proportion of their male patients in which the parasite was found was not inconsiderable and in any case nothing was known of the life historye of the parasite or of possible modifications of its appearance or behaviour in different $\bar{\emptyset}$ environments.

Col. King found it hard to believe that the trichomonas was ever the inhabitant of a normal 7 vagina although sometimes it gave rise to no symptoms. In such cases a close examination ${ }_{0}^{-}$ would show some evidence of vaginitis.

With regard to hyperthermy in the treatment of this condition he thought Capt. Gallagher $\stackrel{\Phi}{\perp}$ would be the first to agree that she was not advocating this treatment. The results obtained $\mathbb{Q}_{\square}$ up to date did not justify this suggestion. The clinical observations were however interesting,
for the treatment produced an effect which it had not been possible to produce by other means, 


\section{THE TREATMENT OF TRICHOMONAS VAGINITIS}

and this justified continuation of the investigation. At present this method could not be accepted as a standard treatment.

Dr. J. MacLennan said that the largest part of her own experience had been in a maternity and child welfare clinic, which was not primarily a venereal disease clinic, but where all the cases which presented signs suspicious of venereal diseases were thoroughly investigated. The majority of the patients were married women and there was no reason to suppose if a diagnosis of venereal disease was not made that there had in fact been venereal disease undiscovered. In trichomonas vaginalis infestations, as Major Bolton had pointed out, the immediate relief from symptoms and signs with stovarsol treatment was striking, but in her experience it was with one particular brand. There were several brands of stovarsol on the market in tablet form, and one of these had been particularly disappointing. Dr. MacLennan attributed this failure to the fact that this tablet did not dissolve and the constituents did not become dispersed over the vaginal lining.

She wondered whether the unknown factor in the resistant case was inherent in the patient's constitution. There might be some patients who, for some reason connected with their physical state, might be particularly susceptible to attack by the trichomonas and equally susceptible to relapse after a certain length of treatment.

Dr. P. Silver said that three of his cases which had been treated with stovarsol for a fortnight had failed to respond but all three cleared up within one week after taking vitamin $\mathrm{C}$ fifty milligrams three times a day. In all three cases enquiry into the diet revealed that the normal vitamin $\mathrm{C}$ intake was practically nil. They were given 150 milligrams of vitamin $\mathrm{C}$ daily for one month and not one had relapsed, although this might have been due more to attention to their general health than to the vitamin. Had the vitamin $\mathrm{C}$ intake been measured in any of the Service cases?

Dr. I. N. Orpwood Price, in response to an invitation for an opinion, said that he had never yet been able to stain dried films so that trichomonads could be demonstrated to students. He had applied all the methods with which he was acquainted but not one of these had been successful.

Dr. Mary Gordon asked if the readers of the papers knew of a method of staining films which was satisfactory. She had collected a few and sent them to the pathologist for dark ground examination but the reports had come back "no trichomonas detected" although she felt certain that they were present.

Col. L. W. Harrison wished to join issue with Col. King if he meant that because he had found gonococci in association with trichomonas infestation it was always there ; such an argument was illogical. Many people must have seen cases of infestation where there was no question of gonococci being there. One could of course admit that the gonococci made a favourable breeding ground for trichomonas.

With regard to staining he remembered with much gratitude that after the meeting which had been referred to, when Col. Glen Liston gave a paper on trichomonas infestation, he had an enjoyable morning with him while Col. Liston demonstrated stained specimens of trichomonas. He would admit that he had some difficulty in identifying them at first, but as soon as he was taught how to do so he had none whatever. Later on he was able to stain them himself with Leishman's stain, rather weaker than is used for blood films but with more prolonged contact. He agreed that the dark ground and the axial illumination methods were perhaps the most practical.

Lt.-Col. A. J. King thought that Col. Harrison had misunderstood him in thinking that he said that he thought the gonococcus was always present. What he meant to say was that it was more often present than it was found and he was surprised that in drawing attention to the importance of a contributory bacterial factor the obvious possibility was so often overlooked.

Capt. Betty Walker'said that she had not realized that the $T$. vaginalis was as resistant as stated. She had found that the vaginitis responded very well to the stovarsol compound, provided it was powdered and not used as a tablet. Her patients were given fourteen tablets in powdered form to use during the subsequent menstrual period after discharge from hospital. The number of relapses appeared to have been reduced to some extent by this method.

Dr. Morna Rawlins said that at Guy's Hospital there had been an improvement in the results of treatment of trichomonas vaginitis since all cases had been swabbed out and then treated with local stovarsol during the menstrual period. She tested all patients for the presence of $T$. vaginalis as a routine very simply by putting a drop of the pus on a slide where there was already a drop of normal saline and in which the movement of the trichomonas could readily be detected by ordinary microscopical observation.

S/Ldr. McGregor asked how many cases were covered in Dr. Morton's survey and whether she could give her scheme of treatment.

Dr. Forgan said he had been a most interested listener to the papers on the topical application of Stovarsol. The question had been asked whether the drug was active against the trichomonas when given by mouth, and attempts had been made to reinforce local treatment by oral administration. The results, however, were not appreciably better. • Atebrin had been recommended both by mouth and topically for the treatment of trichomonal vaginitis, but he understood that results were disappointing. He confirmed what Major Bolton had said, that for a time Stovarsol Vaginal Compound tablets had been unsatisfactory owing to war-time difficulties of manufacture, but he understood that this had now been overcome.

$\mathrm{S} / \mathrm{Ldr}$. Morton, in reply to the discussion, said that she quoted Karnaky's 500 cases in the report on which he divided them into white women and negro women, not married and single. 


\section{THE BRITISH JOURNAL OF VENEREAL DISEASES}

It was not a question so much of whether the state was married or single. The enormous $\stackrel{\oplus}{\oplus}$ proportion of cases occurred in women who had had sexual intercourse.

She had not given arsenical compounds by mouth but in some patients under treatment with $\overline{\overrightarrow{5}}$ arsenicals for syphilis who had had a vaginal discharge under investigation, she had found many $\vec{\sigma}$ dead trichomonas in the vagina.

Col. King did not think that the report of Liston and Lees, when they found trichomonas in only sixteen of their cases, supported her view. But no one had proved that there was a transient stage in the trichomonas, nothing corresponding to a spore or cyst had been found, and it would appear that if trichomonas were passed from females to males it should have been found in a much larger number of cases than 16 out of 400 .

With regard to the question of giving sulphonamide compounds she could not agree with Capt. Gallagher and was opposed to giving sulphonamides for a pure trichomonas vaginitis. There was such a close association between trichomonas and gonococcus that she would never $\overrightarrow{\vec{\omega}}$ give a sulphonamide to a patient unless gonorrhoea was also present. Her difficulty at the moment $\omega^{\omega}$ was patients who had been given a sulphonamide for various conditions; they were sent to her $\omega$ for diagnosis and disposal which was quite impossible. She had seen many cases treated by sulphonamides by other people and thought the results were poor. She had never given them nor $\vec{v}$ allowed them to be given.

She thought treatment was essential during the menstrual period; the vagina was then less acid due to the presence of blood. In hospital the treatment was continued during menstruation and when the patients were discharged stovarsol tablets were given to them to use during the next two subsequent periods.

Dr. McGregor had asked the number of cases which she had quoted. She could not give the exact number but she looked up between 400 and 500 consecutive cases of leucorrhoea and had $\mathscr{S}$ noted the figures of pure trichomonas and those with trichomonas plus gonococcus. The pure $\mathbb{D}$ trichomonas cases were in-patients. The scheme of treatment was a douche of sod. bicarb., two per cent gentian violet paint and the vagina was completely coated by insufflation with 3 stovarsol powder. The duration of treatment depended upon the resistance. It was important to continue treatment during the next two menstrual periods after the case was clinically satis-

factory, lest a relapse should occur due to the alkalinity of the vagina at that time.
A particularly interesting case was sent in to hospital on the 16th March, 1943, the question $\vec{\theta}$ being whether she was to be boarded. This young woman who had been in hospitals for over six $\omega$ months with trichomonas vaginalis infestation was a strong, healthy girl, rather fat, with no physical abnormality and a normal menstrual history. On examination it was found that she had trichomonas vaginalis ; a smear of the epithelial cells showed there was no glycogen present and the vagina, on being tested with a litmus paper, was found to be almost neutral. She had $\bar{O}$ been treated with sulphonamides and stovarsol, and S/Ldr. Morton felt it was useless to try ڤ any of these. The literature had mentioned that oestrin had a beneficial effect, so the girl was given $\mathbb{D}$ stilboestrol in increasing doses which she tolerated very well. She had one milligram three times a day for the first day, two milligrams three times a day on the second day, and three milligrams $\overrightarrow{\overrightarrow{0}}$ three times a day on the third day and that became her daily treatment for one month. At the 3 same time-local treatment with 1 in 500 lactic acid douches was given and carried on during that $\vec{J}$ period. The first examination after the treatment was started was on the 3rd April; clinically $\frac{F}{0}$ she was normal, the vagina was very faintly acid, trichomonas were still present. On the 10th April she appeared normal, the vaginal reaction was weakly acid and a few trichomonas were detected. On the 24th April no trichomonas were found, and she looked perfectly well. On the 1st May the vagina was definitely acid and on staining the epithelial cells revealed granules suggestive 3 of glycogen. The next complete examination was done on the 26th May, when the results were no trichomonas, definitely acid vagina, clinically well, and very definite glycogen granules in the epithelial cells.

This was the only case in which she had tried hormone treatment, but it was beneficial. This might be an interesting factor in the causation of the condition.

In conclusion she would emphasize that she was definitely against the giving of sulphonamides $D$ for a pure trichomonas infestation.

Captain Gallagher, also in reply, said that she still favoured the giving of sulphonamides. Out of 189 cases 60 were proved gonococcal infections and a certain proportion had the definite $\Omega$ clinical appearance of gonorrhoea, also a certain number of these cases were known and admitted contacts of men with proved gonorrhoea which brought one very near the total number of $\bigcirc$ cases treated. On thorough enquiry into the history one found that in many cases there were $N$ strong reasons for the use of sulphonamides.

With regard to Major Bolton's remarks in the very resistant case which she herself had mentioned, acetarsol did produce relief from the symptoms but immediately on cessation of the application of the acetarsol the vaginitis and the discharge recurred. The question of the acetarsol $\stackrel{\Phi}{\mathscr{D}}$ supply being an ineffective batch did not arise because other cases being treated at the same time $\stackrel{\mathcal{P}}{+}$ responded well.

They had not tried vitamin $C$ recently, but it was an interesting method of attack and in $\bar{O}^{\circ}$ many cases both the vitamin intake and other general considerations should be taken into account in the treatment.

She wished to make it clear that while in this series they did not deliberately prolong the $\frac{\mathbb{D}}{2}$ treatment to include the menstrual period they did, of course, treat through a period if it occurred $\frac{\varrho}{\sigma}$ and in resistant cases it was necessary to prolong treatment through the period. With regard to the use of arsenic apart from local treatment she had no figures to illustrate the effect of $\delta$ 


\section{RELIABILITY OF THE WASSERMANN REACTION}

neoarsphenamine in addition to the local treatment. A mumber of cases had been treated for syphilis and trichomonas concurrently, but she did not think there was much effect on the trichomonas by the use of the intravenous arsenic.

\section{ANNOTATION}

\section{RELIABILITY OF THE WASSERMANN REACTION}

In the present issue will be found a paper on the use and significance of serum tests for syphilis by Colonel L. W. Harrison and Brigadier T. E. Osmond. The authors were at some pains to point out the various conditions, both physiological and pathological, which may give rise to false positive results and it has been suggested that this might conceivably engender, in the minds of medical men, a feeling of "Wassermann insecurity." In reality-and a careful consideration of the paper will confirm this-nothing could be further from the truth, and a Wassermann reaction carried out by a competent pathologist is amongst the most reliable of pathological tests which we have at our command. The Wassermann reaction, and particularly the method in question (No. 1 method M.R.C.) has proved itself throughout a number of searching enquiries to be highly specific and reasonably sensitive.

The point which we should like to stress is that it is not the test which is mainly at fault but its interpretation. In the past there has been far too little critical judgment used in assessing the results of Wassermann reactions and even today many practitioners are inclined to say " positive W.R., therefore syphilis." Whilst it is admitted that if we exclude certain tropical and sub-tropical diseases such as yaws, leprosy and malaria there are few conditions which are likely to give a persistently false positive W.R., nevertheless experience has shown that the danger does exist. Not only certain diseases, but some ill-understood physiological conditions do from time to time give positive results with serum tests for syphilis, and the clinician will do well to bear this in mind. The pathologist is not a diagnostician ; it is his job to report the results which he gets, not to assess them, though in difficult cases and where unexpected results are obtained a consultation with him will often prove useful. The Wassermann test, like all other tests, has its limitations ; and when the clinician is faced with the assessment of a result he will do well to bear this in mind. It is when a positive reaction is reported in a case in which there is nothing in the history or clinical signs pointing to syphilis that the greatest difficulty lies. It is no light thing to diagnose syphilis and thereby condemn the patient to the long and somewhat dangerous treatment which such a diagnosis entails. When such a case does occur the clinician should remember the limitations of serum tests and leave no stone unturned to try to discover why the result was positive; he will then go over in his mind the various causes of false positive reactions and seek to exclude them before making a diagnosis of syphilis.

Another further point perhaps needs stressing; most of the conditions met with in this country which are liable to give a fałse positive Wassermann reaction only do so over comparatively short periods, and if repeated tests are carried out over a sufficiently long time the true nature of the condition will usually be revealed. The Wassermann test, particularly that as modified by Richardson, and the Kahn, including the Verification test, are amongst the most reliable tests we have at our disposal if assessed with judgment but they are not 100 per cent perfect. If the clinician will bear this in mind and remember that a positive serum test does not in itself justify a diagnosis of syphilis he will not be likely to go far wrong. The specificity and sensitivity of the Wassermann reactions are probably greater today than at any time in the past, thanks to the work carried out by serologists all over the world; the only proviso is that a reliable technique should be employed and the test carried out by a pathologist of experience. 